\title{
A MESSAGE FROM THE EDITORS
}

This issue marks an important stage in the Journal's development. In our original mission statement we recognized that Modern Intellectual History was likely in the first instance to be devoted to publishing work on intellectual history that was essentially Western in orientation and we looked forward to the day in which it would be possible to extend our reach to non-Western as well as Western history.

In the present issue we are fortunate enough to be able to publish a collection of essays by an important group of South Asian historians who have been struck by the limitations that postcolonial and orientalist historiography have imposed on South Asian intellectual history and by the problems involved in adapting the various languages of Western intellectual history to the circumstances of a colonial world. We publish them in the belief that this is a significant corpus of work which should give intellectual historians Western and non-Western alike cause for reflection and debate.

We are very grateful to one of our Board members, David Armitage, for bringing the work of this group to our attention. But above all we are grateful to Shruti Kapila, whose project this is, for allowing us to publish these essays and for undertaking much of the hard work involved in editing it.

Charles Capper, Anthony La Vopa and Nicholas Phillipson 